\title{
Development and optimization of quantitative PCR for the diagnosis of invasive aspergillosis with bronchoalveolar lavage fluid Prasanna D Khot ${ }^{1}$, Daisy L Koํㅜ, Robert C Hackman ${ }^{1,2}$ and David N Fredricks*1,2
}

Address: ${ }^{1}$ Fred Hutchinson Cancer Research Center, Seattle, WA, USA and ${ }^{2}$ University of Washington, Seattle, WA, USA

Email: Prasanna D Khot - pkhot@fhcrc.org; Daisy L Ko - dko@fhcrc.org; Robert C Hackman - rhackman@fhcrc.org; David N Fredricks* - dfredric@fhcrc.org

* Corresponding author

Published: 29 May 2008

BMC Infectious Diseases 2008, 8:73 doi:10.1 I86/147/-2334-8-73
Received: 3 January 2008

Accepted: 29 May 2008

This article is available from: http://www.biomedcentral.com/I47I-2334/8/73

(C) 2008 Khot et al; licensee BioMed Central Ltd.

This is an Open Access article distributed under the terms of the Creative Commons Attribution License (http://creativecommons.org/licenses/by/2.0), which permits unrestricted use, distribution, and reproduction in any medium, provided the original work is properly cited.

\begin{abstract}
Background: The diagnosis of invasive pulmonary aspergillosis (IPA) remains challenging. Culture and histopathological examination of bronchoalveolar lavage (BAL) fluid are useful but have suboptimal sensitivity and in the case of culture may require several days for fungal growth to be evident. Detection of Aspergillus DNA in BAL fluid by quantitative PCR (qPCR) offers the potential for earlier diagnosis and higher sensitivity. It is important to adopt quality control measures in PCR assays to address false positives and negatives which can hinder accurate evaluation of diagnostic performance.
\end{abstract}

Methods: BAL fluid from 94 episodes of pneumonia in 81 patients was analyzed. Thirteen episodes were categorized as proven or probable IPA using Mycoses Study Group criteria. The pellet and the supernatant fractions of the BAL were separately assayed. A successful extraction was confirmed with a human 185 rRNA gene qPCR. Inhibition in each qPCR was measured using an exogenous DNA based internal amplification control (IAC). The presence of DNA from pathogens in the Aspergillus genus was detected using qPCR targeting fungal I8S rRNA gene.

Results: Human I8S rRNA gene qPCR confirmed successful DNA extraction of all samples. IAC detected some degree of initial inhibition in II samples. When culture was used to diagnose IPA, the sensitivity and specificity were $84.5 \%$ and $100 \%$ respectively. Receiver-operating characteristic analysis of qPCR showed that a cutoff of $13 \mathrm{fg}$ of Aspergillus genomic DNA generated a sensitivity, specificity, positive and negative predictive value of $77 \%, 88 \%, 50 \%, 96 \%$ respectively. BAL pellet and supernatant analyzed together resulted in sensitivity and specificity similar to BAL pellet alone. Some patients did not meet standard criteria for IPA, but had consistently high levels of Aspergillus DNA in BAL fluid by qPCR.

Conclusion: The Aspergillus qPCR assay detected Aspergillus DNA in $76.9 \%$ of subjects with proven or probable IPA when the concentrated BAL fluid pellet fraction was used for diagnosis. There was no benefit from analyzing the BAL supernatant fraction. Use of both extraction and amplification controls provided optimal quality control for interpreting QPCR results and therefore may increase our understanding of the true potential of QPCR for the diagnosis of IPA. 


\section{Background}

Invasive pulmonary aspergillosis (IPA) is a common infection in patients with hematological malignancies and those undergoing hematopoietic cell transplantation [1]. Despite the availability of several active antifungal agents, IPA continues to have a high mortality rate [2]. The diagnosis of IPA remains a challenge $[3,4]$. Most symptoms are non-specific, such as fever, cough, or chest pain, and many patients have no symptoms at all. Although some radiographic findings in the lungs can suggest aspergillosis, such as the presence of a halo sign (ground glass opacity surrounding a nodule) or cavitating nodules, these findings can also be found in subjects with pulmonary zygomycosis or other infections and are thus again not necessarily specific [5]. The failure to make an accurate diagnosis frequently results in the use of empirical antifungal therapy in the suitable immunocompromised host.

Bronchoalveolar lavage (BAL) fluid is routinely used to assess for the presence of fungi at the site of pulmonary infection. Conventional microbiological techniques like culture and histology of BAL fluid are most commonly used for the diagnosis of IPA, but have suboptimal sensitivity, and in the case of culture may take several days [68]. Detection of the fungal cell wall constituents like galactomannan (in serum and BAL fluid) and beta-glucan (in serum) are promising diagnostic alternatives to facilitate the diagnosis of invasive fungal infection, but false positive and false negative results remain problematic with both assays [9-11]. Molecular diagnostic techniques such as nucleic acid detection by PCR are emerging as potentially more sensitive and rapid alternatives to conventional techniques for the diagnosis of IPA [12-19]. Our study focuses on developing a quantitative PCR (qPCR) platform to detect Aspergillus DNA in BAL as an indicator of IPA.

Quantitative PCR has several advantages when used for the detection of Aspergillus spp. First, qPCR is highly sensitive with the potential to detect a few gene copies per reaction, or less than a single genome for multicopy genes such as the rRNA gene. Second, by taking advantage of both conserved and variable regions of genes, primers and probes can be made that are specific for a given genus, species or strain of microbe. Third, qPCR can measure the amount of microbial DNA in a clinical sample, which may be useful for assessing the burden of infection and in distinguishing between colonization and infection. Fourth, multiplexed qPCR reactions can reduce the necessity of running independent qPCRs allowing for the detection of multiple targets or for inclusion of amplification controls in a single reaction. Fifth, qPCR assays can be completed in a few hours, resulting in a rapid turn around time for reporting results. However, to develop an optimal
qPCR assay for diagnosis, several challenges and shortcomings should be addressed to avoid false positive and false negative results [20-22]. False negatives can occur due to suboptimal DNA extraction (i.e. low recovery of DNA and/or the presence of PCR inhibitors), large quantities of human genomic DNA competing with the microbial target for amplification, and suboptimal analytical sensitivity of the qPCR reaction itself (high detection threshold). False positives can occur due to introduction of contamination during sample collection, DNA extraction, and PCR set-up, resulting from the presence of fungi in the environment or fungal PCR product carry-over. In addition, false positives can occur in the setting of suboptimal analytical specificity in the GPCR, resulting from cross-reactivity of the target qPCR assay with other (nontarget) fungi or DNA. Optimal qPCR assays should incorporate controls to assess for these factors contributing to false positive and false negative results, but most studies published to date have not. A major hurdle to the wider adoption of PCR for the diagnosis of invasive fungal infections is the lack of standardization among assays. It is important that investigators in the field adopt standards for ruling out false positive and false negative results, as this will allow for more accurate comparisons among different assay platforms.

Many studies have used BAL fluid for the diagnosis of fungal pneumonia using PCR, but the best fraction of BAL fluid to use for this purpose has not been defined. It is unclear if the majority of Aspergillus DNA in BAL fluid is contained in intact cells or is cell-free DNA that results from lysis of fungi in vivo. We hypothesized that if most of the Aspergillus DNA is present in intact cells, then detection can be maximized by concentrating the cellular fraction of the BAL into a pellet by centrifugation before subjecting this smaller volume to DNA extraction. If cellfree Aspergillus DNA is the dominant form in BAL fluid, then qPCR should detect equal or greater amounts of DNA in this larger supernatant fraction.

To optimize our qPCR assay platform for the diagnosis of IPA, we developed a panel of GPCR assays, including amplification and extraction controls, and modified a DNA extraction technique to increase yields of fungal DNA from BAL fluid. This optimized assay was tested on sequentially obtained BAL samples collected from patients with hematological malignancies or undergoing hematopoietic cell transplantation at the Seattle Cancer Care Alliance who developed pneumonia or pulmonary nodules. In an initial analysis, both the pellet and supernatant fractions of the BAL were assayed to determine the optimal fraction for detecting Aspergillus DNA. The performance of our QPCR assay was compared with the conventional microbiological techniques of culture and histology. 


\section{Methods}

\section{Study population and design}

Patients with hematological malignancies or undergoing hematopoietic cell transplantation at the Seattle Cancer Care Alliance who developed pneumonia or pulmonary nodules underwent bronchoscopy with BAL. BAL fluid remaining after conventional microbiological and cytologic evaluations was processed as noted in the next subsection. This was a retrospective study analyzing BAL fluid samples obtained from April 2002 to July 2003, and was approved by the Institutional Review Board at the Fred Hutchinson Cancer Research Center. This study involved 81 patients, 94 episodes of pneumonia, and 144 BAL samples. Note that multiple lobes were lavaged at the time of bronchoscopy in most subjects, resulting in an average of more than one BAL sample per episode. Analysis was done on an episode basis, with an episode defined as a single radiographically and temporally related pneumonia. If a subject had resolution of pulmonary infiltrates with appearance of a new infiltrate at a later time, this was considered a separate episode. Figure 1 depicts the algorithm used for the diagnosis of IPA using qPCR. Patients with proven or probable IPA were diagnosed using European Organization for Research and Treatment of Cancer/
Mycoses Study Group (EORTC/MSG) criteria [23]. Designation of clinical status was performed by an investigator who was blinded to qPCR results, with host factors, clinical criteria, and microbiological criteria abstracted from the medical record and entered into a relational database.

\section{Processing of BAL fluid}

The starting volume of BAL fluid was in the range of 2 to $5 \mathrm{ml}$. BAL fluid was centrifuged at $3200 \mathrm{rcf}$ for $15 \mathrm{~min}$ at $4{ }^{\circ} \mathrm{C}$. The pellet was resuspended in a small volume of supernatant, with the final pellet fraction having a volume of 100 to $400 \mu \mathrm{l}$, depending on the degree of cellularity. The pellet and the remaining supernatant fraction were frozen in separate tubes at $-80^{\circ} \mathrm{C}$ until DNA extraction.

\section{DNA extraction from BAL fractions}

DNA extraction of clinical samples and PCR set up was performed in a laminar flow hood within a laboratory that was exclusively used for pre-PCR processing. An optimized version of the MasterPure ${ }^{\mathrm{TM}}$ Yeast DNA Purification Kit (Epicentre ${ }^{\circledast}$ Biotechnologies, Madison, WI) was used for BAL DNA extraction. The $100 \%$ isopropanol, $70 \%$ ethanol and DNA grade water used for extraction were filtered in an Amicon Ultra-15 centrifugal filter unit with a

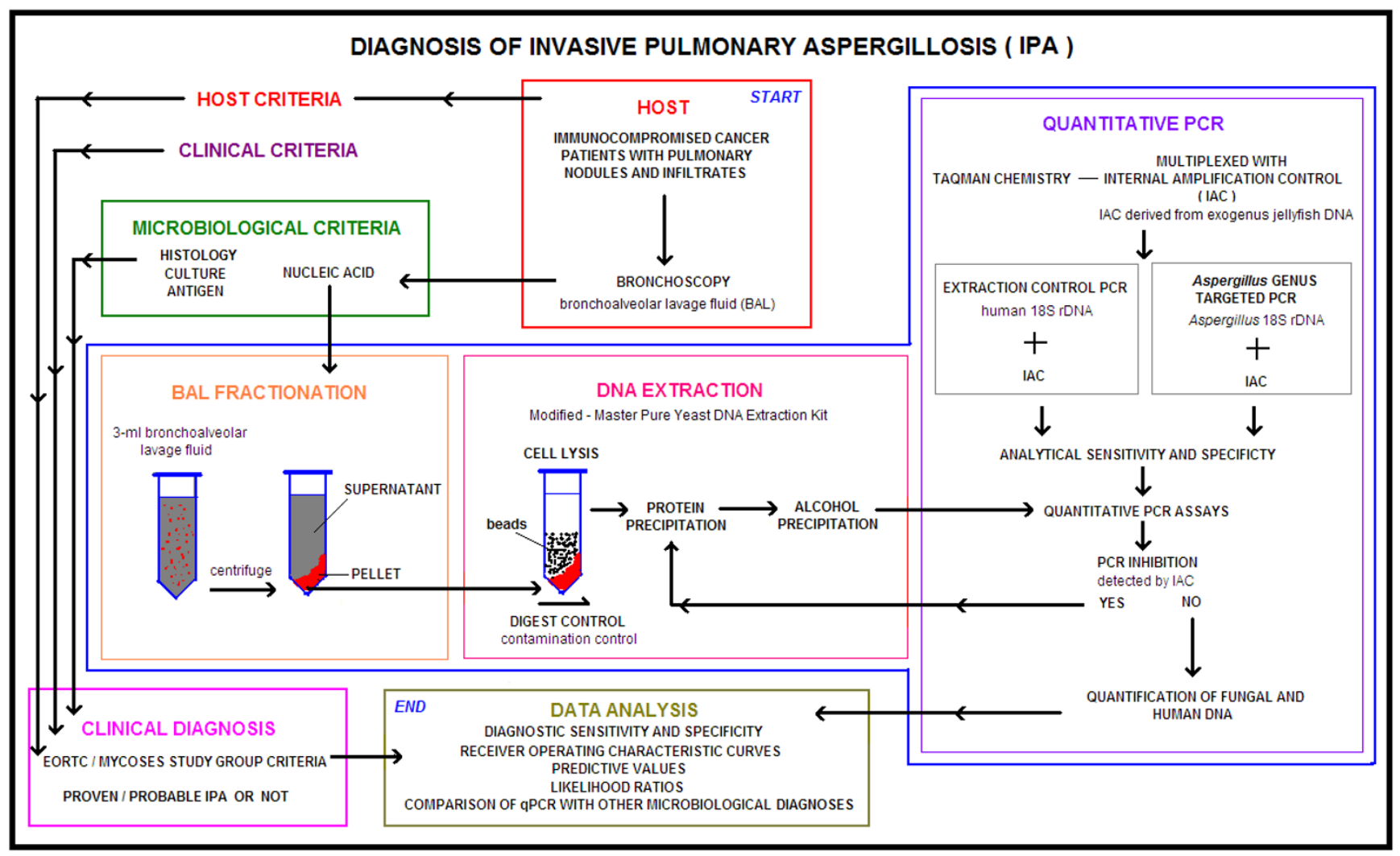

Figure I

Diagnostic approach. Flowchart depicting the algorithm used for the diagnosis of IPA using qPCR. 
molecular weight cut-off (MWCO) of $30 \mathrm{kDa}$ (Millipore Corporation, Billerica, MA). Yeast Cell Lysis ${ }^{\mathrm{TM}}$ solution and MPC Protein Precipitation Reagent ${ }^{\mathrm{TM}}$ were UV irradiated at $240 \mathrm{~mJ} / \mathrm{cm}^{2}$ with samples approximately 15 centimetres from the bulbs (Spectrolinker ${ }^{\mathrm{TM}}$, Westbury, NY). The silicon carbide sharps were washed 10 times in DNA free water and baked at $180^{\circ} \mathrm{C}$ for $48 \mathrm{~h}$. DNA-free microcentrifuge tubes were used with DNA extraction (Eppendorf Biopur tubes, Eppendorf AG, Hamburg, Germany). Sham digest controls consisting of DNA free water were processed with every extraction run serving as negative controls to monitor for fungal contamination.

DNA was independently extracted from the pellet and supernatant fractions of the BAL; no whole BAL was processed. In the case of the supernatant fraction, extraction started with $0.5 \mathrm{ml}$ of the supernatant from the protein precipitation step onwards. For the pellet fraction, an additional bead beating step was included. Two milliliter sterile screw-cap tubes were loaded with silicon carbide sharps of sizes $0.1 \mathrm{~mm}$ and $1 \mathrm{~mm}$ (BioSpec Products, Inc., Bartlesville, OK) at a 1:1 ratio up to a volume equivalent to $250 \mu \mathrm{l}$. Yeast Cell Lysis $^{\mathrm{TM}}$ solution at a volume of $550 \mu \mathrm{l}$ and BAL pellet at $100-400 \mu \mathrm{l}$, or $200 \mu \mathrm{l}$ of water as digest control, were added to the tube. The contents of the tube were homogenized in a FastPrep ${ }^{\oplus}-24$ System (MP Biomedicals, Solon, $\mathrm{OH}$ ) at $5 \mathrm{~m} / \mathrm{s}$ for $60 \mathrm{~s}$. Each tube was incubated at $65^{\circ} \mathrm{C}$ for $45 \mathrm{~min}$ then kept on ice for $5 \mathrm{~min}$. MPC Protein Precipitation Reagen ${ }^{\mathrm{TM}}$ was added at a volume of $325 \mu \mathrm{l}$ for pellet and $450 \mu \mathrm{l}$ for supernatant processing. The tubes were vortexed for $10 \mathrm{~s}$ and centrifuged at 11,000 rcf for $10 \mathrm{~min}$. The resulting supernatant was transferred to a new micro-centrifuge tube containing an equal volume of $100 \%$ isopropanol pre-cooled to $-20^{\circ} \mathrm{C}$. The contents of the tube were mixed thoroughly by inversion and incubated at $-20^{\circ} \mathrm{C}$ for 1 hour. Precipitated DNA was pelleted by centrifugation at $11,000 \mathrm{rcf}$ for $10 \mathrm{~min}$. This supernatant was removed and discarded. The pellet containing DNA was resuspended in $0.5 \mathrm{ml}$ of pre-cooled ($\left.20^{\circ} \mathrm{C}\right) 70 \%$ ethanol and vortexed. The tube was then centrifuged at $11,000 \mathrm{rcf}$ for $5 \mathrm{~min}$. This supernatant was removed to a level just short of disturbing the pellet. The remaining volume of ethanol was allowed to evaporate by air drying for $5 \mathrm{~min}$ within the laminar flow hood. The pellet was resuspended in $100 \mu \mathrm{l}$ of $0.1 \%$ Triton-X prewarmed to $65^{\circ} \mathrm{C}$ then incubated at room temperature for one minute with periodic gentle vortexing. The DNA was either used immediately for qPCR, stored at $-20^{\circ} \mathrm{C}$ overnight or at $-80^{\circ} \mathrm{C}$ for longer periods. If PCR inhibition was detected in the extracted samples, they were reprocessed from the protein precipitation step onwards (see Figure $1)$.

\section{Preparation of fungal genomic DNA}

Genomic DNA from fungi was extracted with an optimized MasterPure ${ }^{\mathrm{TM}}$ Yeast DNA Purification Kit (Epicen- tre ${ }^{\circledast}$ Biotechnologies, Madison, WI) in order to assess assay analytical sensitivity and specificity. Fungi were transferred into micro-centrifuge tubes from liquid media and centrifuged. Cell pellets were washed with $1 \mathrm{ml} 1 \times$ PBS and centrifuged at 10,000 $\mathrm{rcf}$ for $3 \mathrm{~min}$. The supernatant was discarded and cells resuspended in $500 \mu \mathrm{l}$ Yeast Cell Lysis $^{\mathrm{TM}}$ solution. The tube was vortexed at top speed for 10 $\mathrm{s}$. The tube was incubated at $65^{\circ} \mathrm{C}$ for $1 \mathrm{~h}$ and then kept on ice for $5 \mathrm{~min}$. For filamentous fungi, the pellet was ground with a micropestle at the start and during the $65^{\circ} \mathrm{C}$ incubation. Protein Precipitation Reagent ${ }^{\mathrm{TM}}$ was added at a volume of $400 \mu$ l to the tube and vortexed for $10 \mathrm{~s}$. The tube was centrifuged to pellet cellular debris at $11,000 \mathrm{rcf}$ for $10 \mathrm{~min}$. The supernatant was transferred to a new micro-centrifuge tube containing an equal volume of $100 \%$ isopropanol pre-cooled to $-20^{\circ} \mathrm{C}$. The contents of the tube were thoroughly mixed by inversion and incubated at $-20^{\circ} \mathrm{C}$ for $1 \mathrm{hr}$. Precipitated DNA was pelleted by centrifugation at $11,000 \mathrm{rcf}$ for $10 \mathrm{~min}$. The supernatant was removed and discarded. The pellet containing DNA was resuspended in pre-cooled $\left(-20^{\circ} \mathrm{C}\right) 1 \mathrm{ml}$ of $70 \%$ ethanol and vortexed at maximum speed for $10 \mathrm{~s}$. The tube was then centrifuged at $11,000 \mathrm{rcf}$ for $5 \mathrm{~min}$. This supernatant was removed to a level just short of disturbing the pellet. The remaining volume was allowed to evaporate by air drying for $5 \mathrm{~min}$. The pellet was resuspended in $100 \mu \mathrm{l}$ of $0.1 \%$ Triton-X pre-warmed to $65^{\circ} \mathrm{C}$ and incubated at room temperature for $1 \mathrm{~min}$ with periodic gentle vortexing. The total nucleic acid in the extract was quantified using a UV spectrophotometer. For every $149 \mu \mathrm{g}$ of total nucleic acid in the extract, $10 \mathrm{U}$ of RiboShredder ${ }^{\mathrm{TM}}$ RNase Blend (Epicentre ${ }^{\circledast}$ Biotechnologies, Madison, WI) was used to remove RNA. RNA removal was confirmed by visualizing the pre- and post-treatment extract on a $1.5 \%$ agarose gel. DNA was quantified using a Qubit ${ }^{\mathrm{TM}}$ instrument and Quant-iT ${ }^{\mathrm{TM}}$ dsDNA HS Assay Kit (Invitrogen Corporation, Carlsbad, CA).

\section{Quantitative PCR assays}

Quantitative PCR assays in this study were based on Taq$\operatorname{man}^{\mathrm{TM}}$ chemistry and an Applied Biosystems $7500^{\mathrm{TM}}$ realtime instrument was used for detection. To prevent contamination, each PCR master mix without additional water component was filtered through a Microcon YM100 centrifugal filter unit with a MWCO of $100 \mathrm{kDa}$ (Millipore Corporation, Billerica, MA) at $650 \mathrm{rcf}$ for $25 \mathrm{~min}$ and $1500 \mathrm{rcf}$ for an additional $5 \mathrm{~min}$ before use. The additional water was independently filtered with an Amicon Ultra-15 centrifugal filter unit with a MWCO of $30 \mathrm{kDa}$ using. DNA-free microcentrifuge tubes were used with the PCR set up (Eppendorf Biopur tubes, Eppendorf AG, Hamburg, Germany). No-template controls were run with each QPCR assay to monitor contamination. Each extracted BAL sample was run in duplicate reactions. Samples were interpreted as positive if both duplicates showed an increase in normalized relative florescence above the 
background and the multicomponent view demonstrated an increase in absolute florescence (as estimated by the 7500 System SDS software, Applied Biosystems).

\section{(i) Internal amplification control (IAC) $q P C R$}

The IAC qPCR was developed based on a 105 base template derived from the jellyfish aequorin gene which has a sequence of 5'GCCTGGTGCAAAAATTGCTTATCAAATTGAACGGTCAATTGGAAGTGGCGGAAGAACAGCTATTGCAAACGC

CATCGCACAATACCATAAACACACTTGTCTTAG-3' [24]. The amplicon was detected with a forward primer 5 '-GCC TGG TGC AAA AAT TGC TTA TC-3', reverse primer 5'- CTA AGA CAA GTG TGT TTA TGG TAT TG -3' and probe labelled with fluorescein (Quasar670) and quenched with BHQ2: 5'-Quasar670 CTT CCG CCA CTT CCA ATT GAC CGT TCA BHQ2-3' (Biosearch Technologies, Novato, $\mathrm{CA})$. The IAC was multiplexed with the Aspergillus targeted $18 \mathrm{~S}$ qPCR and the human targeted $18 \mathrm{~S}$ extraction control qPCR to monitor inhibition in every qPCR reaction. If inhibition as assessed by $>2$ cycle delay in the IAC threshold cycle was detected, DNA was re-purified and assayed again.

\section{(ii) Extraction control $q P C R$}

Successful DNA extraction was confirmed in all samples with a qPCR targeting the human $18 \mathrm{~S}$ rRNA gene with forward primer 5'- CTC TTA GCT GAG TGT CCC GC -3', reverse primer 5'- CTT AAT CAT GGC CTC AGT TCC GA 3', and probe labelled with fluorescein (FAM) and quenched with TAMRA: 5'-FAM CCG AGC CGC CTG GAT ACC GCA GCT A TAMRA-3'. Each 50- $\mu$ l PCR mixture contained $1 \times$ TaqMan $^{\circledast}$ Buffer A, $6 \mathrm{mM}$ of $\mathrm{MgCl}_{2}, 1 \mathrm{mM}$ of GeneAmp ${ }^{\circledast}$ dNTP Blend (12.5 mM with dUTP), $2.2 \mathrm{U}$ of AmpliTaq Gold ${ }^{\circledast}$ DNA Polymerase, 0.05 U AmpErase Uracil N-glycosylase (all from Applied Biosystems, Foster City, CA), $0.8 \mu \mathrm{M}$ each of forward and reverse human targeted primers, $180 \mathrm{nM}$ of human targeted probe, $0.24 \mu \mathrm{M}$ each of forward and reverse of IAC primers, $180 \mathrm{nM}$ of IAC probe, $0.002 \%$ of Triton-X $100,10^{5}$ copies of IAC template and $5 \mu \mathrm{l}$ of DNA. The PCR cycling conditions consisted of an Uracil N-glycosylase activation at $50^{\circ} \mathrm{C}$ for 2 min, pre-melt at $95^{\circ} \mathrm{C}$ for $10 \mathrm{~min}$ and then 38 cycles of $95^{\circ} \mathrm{C}$ for $15 \mathrm{~s}$ (melt) and $65^{\circ} \mathrm{C}$ for $65 \mathrm{~s}$ (annealing and extension). A standard curve for quantifying human DNA was generated using human genomic DNA (Roche Applied Sciences, Indianapolis, IN) with dilutions ranging from 10,000 to $1 \mathrm{pg}$.

\section{(iii) Aspergillus targeted I8S qPCR}

The Aspergillus targeted qPCR amplified a $114 \mathrm{bp}$ segment of the Aspergillus 18S rRNA gene with forward primer 5'GAT AAC GAA CGA GAC CTC GG -3', reverse primer 5'AGA CCT GTT ATT GCC GCG C -3' and probe 5'-FAM CTT
AAA TAG CCC GGT CCG C BHQ-3' with minor groove binding modification. Each 50- $\mu$ PCR mixture contained $1 \times$ TaqMan $^{\circledast}$ Buffer A, $6 \mathrm{mM}$ of $\mathrm{MgCl}_{2}, 1$ mM of GeneAmp ${ }^{\circledast}$ dNTP Blend (12.5 mM with dUTP), $2.2 \mathrm{U}$ of AmpliTaq Gold $^{\circledast}$ DNA Polymerase, 0.05 U AmpErase ${ }^{\circledast}$ Uracil N-glycosylase (all from Applied Biosystems, Foster City, CA), 0.8 $\mu \mathrm{M}$ each of forward and reverse Aspergillus targeted primers, $200 \mathrm{nM}$ of Aspergillus targeted probe, $0.4 \mu \mathrm{M}$ each of forward and reverse of IAC primers, $190 \mathrm{nM}$ of IAC probe, $0.002 \%$ of Triton-X $100,10^{5}$ copies of IAC template and 5 $\mu \mathrm{l}$ of DNA. The PCR cycling conditions consisted of an Uracil N-glycosylase activation at $50^{\circ} \mathrm{C}$ for $2 \mathrm{~min}$, premelt at $95^{\circ} \mathrm{C}$ for $10 \mathrm{~min}$ and then 45 cycles of $95^{\circ} \mathrm{C}$ for 15 $\mathrm{s}$ (melt) and $65^{\circ} \mathrm{C}$ for $65 \mathrm{~s}$ (annealing and extension). A standard curve for quantifying Aspergillus DNA was generated using Aspergillus fumigatus genomic DNA (ATCC \# MYA-1163) dilutions ranging from $1000 \mathrm{pg}$ to $30 \mathrm{fg}$. All positive Aspergillus qPCRs for the first 48 episodes were subjected to sequencing using Big Dye terminators and an Applied Biosystems capillary sequencer to confirm identity with the expected target.

\section{Analytical specificity testing}

The analytical specificity of the Aspergillus qPCR was assessed by testing 1000 pg of genomic DNA from 29 different fungal species spanning 15 genera grown in culture. The following clinically or phylogenetically relevant fungal pathogens were chosen: Aspergillus fumigatus (ATCC \# MYA-1163), Aspergillus oryzae (ATCC \# 20719), Aspergillus ustus (ATCC \# 20063), Aspergillus candidus (ATCC \# 20022), Aspergillus terreus (ATCC \# 10070), Aspergillus flavus (ATCC \# MYA-3631), Candida albicans (ATCC \# 90028), Candida glabrata (ATCC \# 90876), Candida kefyr (ATCC \# 28838), Candida guilliermondii (ATCC \# 90877), Candida lusitaniae (ATCC \# 42720), Candida dubliniensis (ATCC \# MYA-580), Scedosporium apiospermum (ATCC \# 28206), Scedosporium prolificans (ATCC \# 90468), Paecilomyces variotti (ATCC \# 10865), Penicillium chrysogenum (ATCC \# 10108), Rhizopus oryzae (ATCC \# 10260), Rhodotorula glutinis (ATCC \# 16726), Absidia corymbifera (ATCC \# 14058), Fusarium solani (ATCC \# 56480), Mucor racemosus (ATCC \# 42647), Rhizomucor miehei (ATCC \# 46345), Cunninghamella bertholletiae (ATCC \# 42155), Trichosporon cutaneum (ATCC \# 38300), Candida parapsilosis (clinical isolate), Candida tropicalis (clinical isolate), Candida krusei (clinical isolate), Saccharomyces cerevisiae (Novagen, Madison, WI), and Cryptococcus neoformans (ATCC \# 28958D5). Cross-reactivity with $1 \mu \mathrm{g}$ of human genomic DNA was also assessed.

\section{Data analysis}

Quantitative PCR results were compared with clinical diagnoses based on the EORTC/MSG criteria. Sensitivity, specificity and positive and negative likelihood ratios with their associated 95\% confidence intervals were calculated. 
The negative and positive predictive values (NPV and PPV) were also calculated for these sequentially obtained samples. These diagnostic parameters were also calculated for culture, histology and both culture and histology combined. A receiver-operating characteristic (ROC) analysis was done using a computer program written with MathWorks MATLAB ${ }^{\circledR}$ software to assess how changing qPCR detection threshold affects sensitivity and 1-specificity.

\section{Results}

\section{Demographic characteristics of the patient population}

Of the 81 subjects with pneumonia or pulmonary nodules studied, $60(74.1 \%)$ underwent hematopoietic cell transplantation and the remainder of the subjects had a diagnosis of leukaemia, lymphoma or another neoplastic condition (see Table 1). Accordingly, the study population represents a group of patients at very high risk for invasive aspergillosis based on risk factors such as underlying malignancy, neutropenia and use of steroids.

\section{Analytical sensitivity and specificity of the qPCR assays}

The Aspergillus qPCR standard curve of genomic Aspergillus DNA consistently yielded $\mathrm{R}^{2}$ (goodness-of-fit) values > 0.98 , which enabled quantification. The Aspergillus qPCR could reliably detect down to a threshold cycle $(\mathrm{Ct})$ of 41 which is approximately equivalent to $1 \mathrm{fg}$ of Aspergillus genomic DNA or a single copy of the target $18 \mathrm{~S}$ rRNA gene.
To determine the specificity of the Aspergillus qPCR, $1 \mu \mathrm{g}$ of human DNA and 1000 pg of fungal DNA from 29 species spanning 15 genera were tested in the Aspergillus qPCR assay. Only Penicillium notatum and Paecilomyces variotii had significant cross-reactivity, with similar levels of Aspergillus DNA reported with addition of $1000 \mathrm{pg}$ DNA from these species. Cross-reactivity studies of the Aspergillus qPCR with human DNA revealed that $10 \mathrm{fg}$ of Aspergillus DNA could be successfully amplified in the presence of $1 \mu \mathrm{g}$ of human DNA per reaction. In actual BAL clinical samples, as little as $20 \mathrm{fg}$ of Aspergillus DNA was detected in the presence of $550 \mathrm{ng}$ of human DNA per reaction. These results demonstrate that very small quantities of Aspergillus DNA ( $<1$ genome) can be detected in a background of large amounts of human DNA ( $10^{9}$ fold excess DNA by mass) using this assay. BAL samples from the first 48 episodes consisting of 10 true positives where an amplification product was detected were sequenced and confirmed to have DNA that matched the Aspergillus genus for each episode. Based on this high concordance rate sequencing was not performed for the subsequent 46 episodes.

The analytical sensitivity of the human $18 \mathrm{~S}$ rRNA gene targeted extraction control qPCR was tested with human genomic DNA. The extraction control qPCR could reliably detect down to $37 \mathrm{Ct}$ which is approximately equivalent to $1 \mathrm{pg}$ of human genomic DNA or one-third of a human genome or 88 copies of the target $18 \mathrm{~S}$ rRNA gene. The

Table I: Demographic characteristics in $8 \mathrm{I}$ subjects.

\begin{tabular}{|c|c|c|c|}
\hline \multirow[t]{2}{*}{ Characteristic } & \multicolumn{2}{|c|}{ Patients with: } & \multirow[t]{2}{*}{ Total } \\
\hline & Proven or Probable IPA & No IPA & \\
\hline \multicolumn{4}{|l|}{ Sex: } \\
\hline Male & 7 & 42 & 49 \\
\hline Female & 6 & 26 & 32 \\
\hline \multicolumn{4}{|l|}{ Age (years): } \\
\hline Median & 60.91 & 50.40 & 53.68 \\
\hline Range & $37.09-73.39$ & $17.97-72.45$ & $17.97-73.39$ \\
\hline \multicolumn{4}{|l|}{ Transplant type: } \\
\hline Allogeneic & 6 & 40 & 46 \\
\hline Autologous & 2 & 12 & 14 \\
\hline Non-Transplant & 5 & 16 & 21 \\
\hline \multicolumn{4}{|l|}{ Underlying disease: } \\
\hline ALL (Acute Lymphoblastic Leukemia) & 0 & 8 & 8 \\
\hline AML (Acute Myeloid Leukemia) & 4 & 12 & 16 \\
\hline AMM (Agnogenic Myeloid Metaplasia) & 1 & 2 & 3 \\
\hline AMML (Acute Myelomonocytic Leukemia) & 0 & 4 & 4 \\
\hline CLL (Chronic Lymphocytic Leukemia) & 0 & 3 & 3 \\
\hline CML (Chronic Myeloid Leukemia) & 0 & 7 & 7 \\
\hline HD (Hodgkin's Disease) & 1 & 6 & 7 \\
\hline NHL (Non Hodgkin's Lymphoma) & I & 8 & 9 \\
\hline MM (Multiple Myeloma) & 3 & 4 & 7 \\
\hline RA (Refractory Anemia) & 1 & 6 & 7 \\
\hline Other & 2 & 8 & 10 \\
\hline
\end{tabular}


standard curve of human genomic DNA consistently yielded R2 (goodness-of-fit) values $>0.98$ for the human $18 \mathrm{~S}$ rRNA gene qPCR, which enabled quantification of amounts of cellular material in BAL fluid.

\section{Extraction control qPCR}

The extraction control qPCR qualitatively confirmed successful DNA extraction and estimated the amount of human genomic DNA present in all 144 BAL samples. The median amount of human genomic DNA per BAL pellet was $2.08 \mu \mathrm{g} /$ pellet (52.1 ng per qPCR reaction) with a range of $9 \mathrm{ng}$ to $58.8 \mu \mathrm{g}$ per pellet. The amount of genomic DNA in the supernatant fraction was relatively low at a median of $88.8 \mathrm{ng} / \mathrm{ml}$ of BAL supernatant and had a range of $0.05 \mathrm{ng}$ to $22.43 \mu \mathrm{g}$ per ml BAL supernatant.

\section{Internal amplification control analysis of PCR inhibition}

The IAC signal in the no-template controls was compared with the IAC signal of the BAL sample. A delay of $2 \mathrm{Ct}$ (equivalent to a 3 -fold change in quantity) or greater in duplicate QPCR reactions was used as a cut-off to classify a sample as having significant qPCR inhibition. The IAC multiplexed with the Aspergillus $18 \mathrm{~S}$ was more useful in detecting inhibition when compared with the IAC multiplexed with the extraction control assay. This is because the IAC signal in the extraction control was at a severe competitive disadvantage due to the large amounts of human DNA present in each sample. The IAC multiplexed with the Aspergillus $18 \mathrm{~S}$ assay detected significant inhibition in 11 samples. Inhibition in all these samples was overcome by re-extraction from the protein precipitation step onwards without significant loss of DNA as assessed by the extraction control qPCR (Fig. 1). When the reextracted samples were assayed again, the IAC did not detect any inhibition.

\section{Contamination control}

Sham digest controls were negative for Aspergillus DNA, showing that no fungal contamination was evident in the DNA extraction reagents. No-template controls were also negative, showing that fungal DNA contamination was not detected in the PCR reagents.

\section{Determination of the optimal fraction for detection of Aspergillus DNA in BAL fluid}

After processing 66 BAL fluid samples from 48 episodes of pneumonia, data analysis was done to evaluate which fraction of BAL fluid contains the most Aspergillus DNA. Ten episodes were categorized as proven or probable IPA in this cohort of 48 episodes; within these 10 episodes, Aspergillus DNA was detected in 7 of 10 for the pellet fraction and in only 4 of 10 for the supernatant fraction. All positive supernatant fractions also had a positive pellet fraction. Of all qPCR positive BALs, an average of $98.3 \pm$
3.8\% of total Aspergillus DNA from both fractions was seen in the pellet. Analysis of BAL pellet and supernatant results together conferred sensitivity and specificity identical to that of BAL pellet alone. It should be noted that although the supernatant fraction had low sensitivity $(40 \%)$, it was highly specific in identifying episodes with proven or probable IPA (specificity 100\%). Since BAL fluid supernatant did not appear to add meaningfully to the diagnostic yield, further analysis of BAL samples focused on analysis of BAL pellet fractions.

\section{Diagnostic utility of the Aspergillus qPCR, culture and histology}

Table 2 summarizes the key diagnostic parameters of the qPCR assay, culture, and histology in detecting the presence of Aspergillus in BAL fluid. ROC analysis of qPCR showed that a cut-off of $13 \mathrm{fg}$ of Aspergillus genomic DNA per BAL pellet (corresponding to approximately 41 cycles) generated good sensitivity and specificity (Fig. 2). Based on this cut-off, the Aspergillus qPCR assay detected 10 of 13 episodes with proven or probable IPA (sensitivity $76.9 \%$ ) and 8 out of 81 episodes without proven or probable IPA (specificity 90.1\%). The positive and negative predictive values were $58 \%$ and $94 \%$. For all BALs with any Aspergillus DNA detected by qPCR, the median quantity of Aspergillus DNA was $173 \mathrm{fg}$ with a range of $4 \mathrm{fg}$ to > 1500 pg per pellet.

BAL culture was somewhat more sensitive than qPCR in detecting IPA (sensitivity $84.6 \%$ ) and had high specificity $(100 \%)$. Histology on the other hand was less sensitive $(53.8 \%)$, but had high specificity $(100 \%)$. When culture and histology were used in combination, the sensitivity increased slightly to $85.7 \%$ and specificity remained at $100 \%$. There was only a single episode with proven or probable IPA in which the histology was positive when the culture was negative. For this episode, the Aspergillus qPCR was convincingly positive with 2 pg of Aspergillus DNA found in the pellet. Two episodes with proven or probable IPA which were culture positive were not positive for qPCR or histology. It should be noted that in these episodes the culture was positive for Aspergillus at a single $\mathrm{CFU}$ level. One episode with proven or probable IPA showed no evidence of Aspergillus by culture or histology and was also negative by Aspergillus qPCR-this subject had a lung biopsy shortly after BAL fluid acquisition that confirmed IPA.

The Pearson correlation coefficient (r) calculated between the fungal burden estimated by GPCR and the number of colony forming units detected by culture in BAL was 0.93 ( $95 \%$ C.I. of $0.85-0.97, \mathrm{df}=25, \mathrm{p}<0.01)$, suggesting a strong relationship between these two independent measures of fungal burden. The $95 \%$ confidence intervals were estimated based on the Fisher r-to-z transformation. 


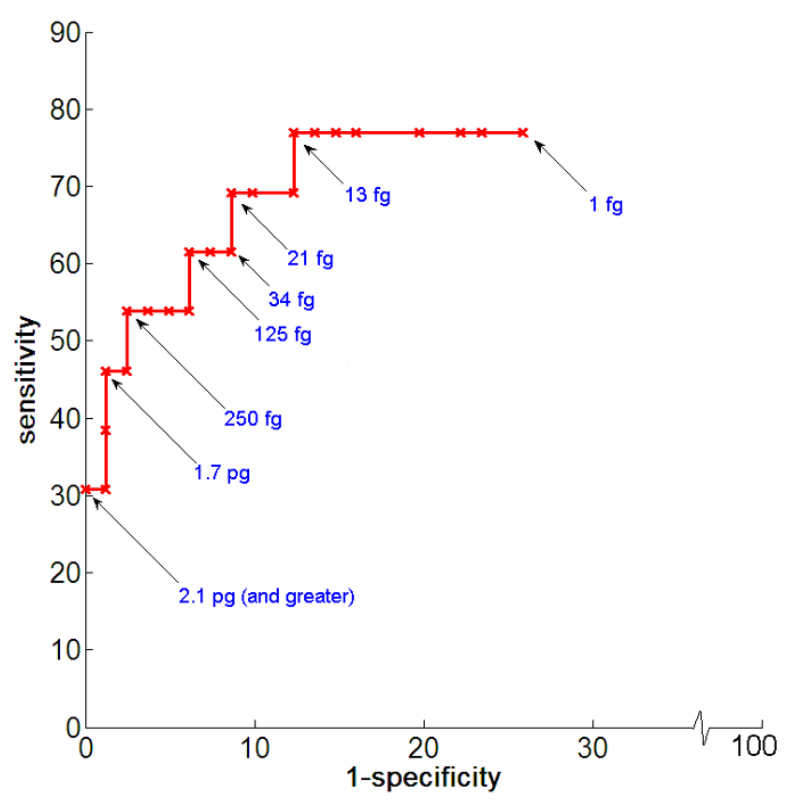

\section{Figure 2}

Receiver-operating characteristic (ROC) analysis. ROC curve depicting sensitivity versus I-specificity of Aspergillus qPCR assay as a function of detection threshold of fungal burden in the BAL pellet $(\mathrm{I} \mathrm{pg}=1000 \mathrm{fg})$. One genome of $A$. fumigatus corresponds to about $30-\mathrm{fg}$ of genomic DNA and is estimated to have 28 copies of the target I8S rRNA gene.

\section{False positive (FP) and false negative (FN) results based on qPCR}

Tables 3 and 4 show information about the false positive and false negative cases as identified by qPCR. Some patients did not meet standard criteria for IPA, but had consistently high levels of Aspergillus DNA in BAL fluid by qPCR based on repeated assays (Table 3). Since the notemplate controls and digest controls were consistently negative, the FPs could not be directly attributed to contamination from DNA extraction or qPCR reagents.

All 3 FNs were negative for histology (Table 4). One (patient \#9) was also negative for culture and the other two FNs (patient \# 10 and 11) had positive culture values reported at a level of $1 \mathrm{CFU}$. These low or negative culture values could potentially reflect lower fungal burden in the BALs which could impact detection by qPCR. The IAC analysis ruled out PCR inhibition as a cause for FNs. In addition, the human genomic DNA amounts in the BAL pellets of FN samples were well within the tested limits of cross-reactivity with amplification by Aspergillus qPCR and hence inhibition due to human genomic DNA overload does not appear to be a factor affecting FN results. It is worthy to note that FN patient \# 9 had the lowest amount of human genomic DNA per reaction of the entire study at
$0.23 \mathrm{ng}$ (Table 4). This could imply that enough cellular mass was not sampled during bronchoscopy which could in turn affect the chance of sampling fungal cells from the potential site of infection.

\section{Discussion}

Despite the availability of new mould-active antifungal medications such as extended spectrum azoles (voriconazole, posaconazole) and echinocandins, aspergillosis remains a significant cause of death in patients with cancer. Delays in the institution of appropriate antifungal therapy may contribute to the high mortality seen with IPA, and the diagnosis of aspergillosis remains a clinical challenge, enhancing the potential for delay [1,3]. Molecular diagnostic techniques such as detection of Aspergillus DNA in BAL fluid using PCR are promising approaches that may facilitate rapid diagnosis, but published studies [12] tend to lack key quality control standards that are useful in identifying problems with false negative and false positive results within a study. Furthermore, the lack of appropriate controls affects the ability to coherently compare different published diagnostic PCR platforms for IPA $[12,21,22,25]$. We developed a qPCR approach for the diagnosis of IPA that incorporates rigorous quality control steps designed to determine if fungal contamination is introduced at the DNA extraction or PCR set up stages, if human DNA is present in the extracted samples and at what level (extraction control), if PCR inhibitors are present after DNA extraction and to what extent they cause inhibition (internal amplification control), and if large amounts of human genomic DNA impede the Aspergillus qPCR.

Many studies have been published describing various PCR assays for the diagnosis of IPA using BAL fluid, but the distribution of Aspergillus DNA in BAL fluid has not been systematically evaluated. We assayed the BAL pellet and supernatant fractions separately for the first 66 BALs (equivalent to 48 episodes) in order to identify the most useful fraction for diagnosis. Our results showed that 98.3\% of Aspergillus DNA in BAL fluid is cell-associated, most likely as either intact fungal cells or as fungi engulfed by leukocytes. The most significant implication of this result is that the diagnostic yield may increase by centrifuging large volumes of BAL fluid and subjecting the pellet to a single extraction. There was no diagnostic benefit from analyzing BAL supernatant as it was positive only when the pellet was positive for Aspergillus DNA. The Aspergillus DNA detected in the supernatant may have resulted from low-level lysis of Aspergillus cells and release of DNA either in vivo (bronchial lining fluid), or in vitro after BAL fluid collection. Attempts to concentrate Aspergillus DNA in the supernatant fraction using ultrafiltration provided no additional value but rather resulted in losses of DNA when compared to the original supernatant 
Table 2: Summary of diagnostic performance in the detection of IPA.

\begin{tabular}{|c|c|c|c|c|c|c|c|}
\hline $\begin{array}{c}\text { Diagnostic } \\
\text { assay }\end{array}$ & BAL fraction & Sensitivity (\%) & Specificity (\%) & $\begin{array}{l}\text { Positive } \\
\text { Predictive } \\
\text { Value (\%) }\end{array}$ & $\begin{array}{l}\text { Negative } \\
\text { Predictive } \\
\text { Value (\%) }\end{array}$ & $\begin{array}{l}\text { Positive } \\
\text { Likelihood } \\
\text { Ratio }\end{array}$ & $\begin{array}{c}\text { Negative } \\
\text { Likelihood } \\
\text { Ratio }\end{array}$ \\
\hline qPCR, $13 \mathrm{fg}$ & pellet & $76.9(50-92)$ & $87.7(79-93)$ & 58 & 94 & $8.63(3.2-11.9)$ & $0.33(0.1-0.7)$ \\
\hline qPCR, I $3 \mathrm{fg}$ & supernatant & $40(17-69)$ & $97.3(86-99)$ & 80.02 & 85.70 & $\begin{array}{c}14.8(1.9- \\
118.1)\end{array}$ & $0.62(0.37-1)$ \\
\hline Culture & $\begin{array}{c}\text { whole } \\
\text { (unfractionated) }\end{array}$ & $84.6(58-96)$ & $100(95-100)$ & 100 & 97.6 & infinity & $0.15(0.04-0.6)$ \\
\hline Histology & $\begin{array}{c}\text { whole } \\
\text { (unfractionated) }\end{array}$ & $53.8(29-77)$ & $100(95-100)$ & 100 & 93.1 & infinity & $0.46(0.3-0.8)$ \\
\hline $\begin{array}{l}\text { Culture or } \\
\text { Histology }\end{array}$ & $\begin{array}{c}\text { whole } \\
\text { (unfractionated) }\end{array}$ & $85.7(60-96)$ & $100(95-100)$ & 100 & 97.7 & infinity & $0.99(0.04-0.5)$ \\
\hline
\end{tabular}

The range of values within brackets are estimated for a confidence interval of $95 \%$. Thirteen femtograms (fg) of Aspergillus DNA was selected as our threshold for a positive PCR assay result, and is approximately equal to I/3rd of an Aspergillus fumigatus genome. The supernatant fraction of the BAL was assayed for the first 48 episodes.

extract (data not shown). The BAL fluid pellet appears to be the best fraction for use in the diagnosis of IPA.

Aspergillus conidia are ubiquitous in the environment, creating the potential for false positive fungal PCR results when highly sensitive PCR assays are employed [21]. Fungal cells or fungal DNA can enter the assay process at numerous points, including at the time of BAL collection, during DNA extraction, or at qPCR set up. UV irradiation and ultrafiltration have been previously used to control PCR contamination [26-28]. Apart from processing samples in a laminar flow hood within a laboratory that was exclusively used for pre-PCR processing, we used UV irradiation, filtration of solutions, and baking of beads and glassware as additional tools to eliminate potential contaminants present in the extraction and PCR reagents. The Yeast Cell Lysis Solution ${ }^{\mathrm{TM}}$ and the Protein Precipitation Reagent $^{\mathrm{TM}}$ (Epicentre $^{\circledast}$ Biotechnologies, Madison, WI) used in DNA extraction could be UV irradiated without loss of function (data not shown). The silicon carbide sharps used in the bead beating step of DNA extraction were specifically chosen from a wide array of materials for their ability to remain chemically and physically stable through a 2-day baking period required to eliminate any contaminating nucleic acids. The organic solvents used in DNA extraction were filtered through a membrane with MWCO of $30 \mathrm{kDa}$. The qPCR mastermix reagents were carefully selected such that they could all be filtered through a membrane of $100 \mathrm{kDa}$ MWCO. The nucleotide cut-off for a $30 \mathrm{kDa}$ filter was 60 bases of single stranded DNA and 50 bp double stranded DNA, and for a $100 \mathrm{kDa}$ filter was 300 bases single stranded DNA and 125 bp double stranded DNA. Even though our Aspergillus qPCR amplicon was $114 \mathrm{bp}$ long (estimated MW of $70 \mathrm{kDa}$ in its double stranded form), we could consistently prevent contamination of the PCR reagents. To minimize any contamination emerging from the IAC qPCR, the IAC primers, probe and template, which were multiplexed with the target qPCR assays, were also filtered as part of the mastermix. The size of the IAC template was designed to be 105 bases long such that it could easily filter through a membrane of $100 \mathrm{kDa}$ MWCO. Another source of contamination in PCR assays may arise from amplicon carry-over contamination from previous PCR runs of the same assay. In addition to strictly isolating pre- from post-PCR work, a uracil-N-glycosylase (UNG) enzyme step was incorporated prior to PCR in combination with use of the nucleotide 2'-deoxyuridine 5'-triphosphate (dUTP) to degrade previous PCR products and prevent carry-over contamination. The water-only sham digest controls and no-template PCR controls used with every experiment were consistently negative confirming that we were able to control contamination originating from the DNA extraction and PCR set ups.

Another factor contributing to FPs can be cross-reactivity of the Aspergillus qPCR assay with non-Aspergillus fungi. Extensive analytical specificity testing showed that among the 23 non-Aspergillus fungal species, our Aspergillus qPCR assay had significant cross-reactivity only with Penicillium chrysogenum and Paecilomyces variotii. P. chrysogenum is a ubiquitous fungus closely related to A. fumigatus. It is rarely associated with human opportunistic infections. $P$. variotii is an opportunistic human pathogen, but voriconazole, which is considered first line therapy targeting Aspergillus species, is also active against $P$. variotii. Thus the clinical ramifications of incorrectly calling a Paecilomyces infection an Aspergillus infection are likely to be small. The galactomannan antigen assay for diagnosis of aspergillosis is also susceptible to false positive results due to crossreactivity with antigens from these two fungal species [10].

Although qPCR assays can detect down to a few target molecules of template per reaction, DNA extraction of fungal pathogens from clinical samples remains the bot- 
Table 3: False positive cases.

\begin{tabular}{|c|c|c|c|c|}
\hline Pt. & Aspergillus DNA (fg/pellet) & BAL Culture & Clinical Diagnosis & $\begin{array}{l}\text { Computed tomography scan results and other clinical } \\
\text { information }\end{array}$ \\
\hline 1 & 5230 & negative & $\mathrm{DAH}$ & $\begin{array}{c}\text { Organizing pneumonia on lung biopsy with pulmonary } \\
\text { hemorrhage; treated with ambisome empirically; No IPA at } \\
\text { autopsy }\end{array}$ \\
\hline 2 & 230 & negative & BOOP & $\begin{array}{c}\text { Bilateral patchy opacities; no mould active antifungal therapy } \\
\text { given }\end{array}$ \\
\hline 3 & 60 & negative & Unknown & $\begin{array}{c}\text { Nodular right middle lobe infiltrate treated with levofloxacin; } \\
\text { exposure to hay }\end{array}$ \\
\hline 4 & 340 & negative & IPA & $\begin{array}{c}\text { Multiple bilateral nodules; treated as IPA with voriconazole + } \\
\text { caspofungin }\end{array}$ \\
\hline 5 & 320 & negative & $\mathrm{DAH}$ & $\begin{array}{c}\text { Bilateral geographic grounds glass opacities; treated with } \\
\text { caspofungin }\end{array}$ \\
\hline 6 & 80 & negative & BOOP & $\begin{array}{l}\text { Numerous bilateral ground glass opacities; treated with } \\
\text { prednisone but no antifungal therapy }\end{array}$ \\
\hline 7 & 170 & negative & Influenza pneumonia/PCP & $\begin{array}{l}\text { Left lung infiltrates; no antifungal therapy except for } \\
\text { Pneumocystis }\end{array}$ \\
\hline
\end{tabular}

Additional information about false positive (FP) cases as identified by qPCR. Pt.: patient; BOOP: Bronchiolitis obliterans with organizing pneumonia; DAH: Diffuse alveolar hemorrhage; PCP: Pneumocystis pneumonia.

tleneck of PCR diagnostics [29-31]. Each BAL sample may consist of sterile saline (lavage fluid), fungal cells, biological components which may be PCR inhibitors (e.g. heme and mucus), and a large amount of human cells. Our previous work evaluated the utility of 6 commercial fungal DNA extraction kits [30]. Based on optimizing fungal DNA yields and minimizing FP and FN results, we selected the MasterPure ${ }^{\mathrm{TM}}$ Yeast DNA Purification Kit (Epicentre $^{\circledast}$ Biotechnologies, Madison, WI) for this study. The DNA extraction protocol was further optimized by adding silicon carbide sharps for lysis of fungal cell wall which significantly enhanced extraction yields. The extraction control qPCR qualitatively confirmed successful extractions and gave a quantitative measure of the amount of human genomic DNA present in every BAL extract. In addition, it helped guarantee that the BAL fluid contacted a human mucosal surface and that DNA was not significantly degraded. Although processing fungal cells in parallel to asses extraction efficiency has been suggested as a more accurate measure, such an approach brings with it the high probability of introducing fungal contamination in the pre-PCR processing lab and is thus a serious drawback. We avoided processing and extraction of fungal cells from external sources to minimize the potential for false positive PCR results. We verified the ability of our Aspergillus qPCR assay to successfully amplify $10 \mathrm{fg}$ of $A$. fumigatus genomic DNA ( $<1$ Aspergillus genome) in the presence of $1 \mu \mathrm{g}$ of human genomic DNA per reaction $\left(10^{9}\right.$ fold excess human DNA). The human $18 \mathrm{~S}$ rRNA gene PCR extraction control measurements helped validate that human genomic DNA in actual PCR reactions derived from BAL fluid was well within these limits, providing evidence that human DNA did not interfere with assay performance leading to false negative results.
It has been suggested that an IAC is critical for assessing PCR inhibition in every sample to rule out inhibition as a cause for FNs [20,32]. Very few studies related to fungal PCR diagnostics analyzing BAL fluid have incorporated an IAC $[33,34]$, only one of which focused on Aspergillus detection in BAL. Our IAC was a truncated version of an exogenous DNA template derived from the jellyfish aequorin gene previously used in PCR studies for the diagnosis of cytomegalovirus disease [24]. Known amounts of IAC template introduced in the multiplexed qPCR mastermix enabled reliable quantification of inhibition in the Aspergillus or extraction control qPCRs. Because the IAC was added during the qPCR stage, it was unaffected by other variables of the process (like DNA extraction) and therefore it exclusively monitored inhibition in qPCR. In addition, the multiplexed IAC amplified with primers and probe independent from the target and its reaction kinetics were optimized such that it did not affect the analytical sensitivity of the target qPCR assay (as confirmed by the positive A. fumigatus standards in each experiment). The IAC qPCR detected inhibition in 7.6\% (11 out of 144) of the BAL samples. Re-extraction of DNA eliminated PCR inhibition in all samples without significant losses of DNA. Therefore, the IAC ruled out qPCR inhibition as a cause for FNs in this study. It is also noteworthy to mention that the IAC qPCR multiplexed with the Aspergillus qPCR assay did not manifest any inhibition even in the presence of human genomic DNA as high as $1.5 \mu \mathrm{g}$ per reaction. This implies that the IAC was monitoring for qPCR inhibition independent of the large quantities of human genomic DNA found in extracted BAL fluid.

A ROC curve of the Aspergillus qPCR assay depicted diagnostic sensitivity versus 1-specificity as a function of detec- 
Table 4: False negative cases.

\begin{tabular}{cccccc}
\hline Pt. & BAL Culture & BAL Histology & Clinical Diagnosis & $\begin{array}{c}\text { Human DNA (ng per } \\
\text { reaction) }\end{array}$ & $\begin{array}{c}\text { CT scan results and other clinical } \\
\text { information }\end{array}$ \\
\hline 8 & negative & negative & IPA & 0.23 from I BAL & $\begin{array}{c}\text { No evidence of IPA in BAL; patchy bilateral } \\
\text { infiltrates; lung biopsy I week later confirmed } \\
\text { IPA by culture and histology }\end{array}$ \\
9 & positive & negative & IPA DAH Staphylococcus \\
pneumonia & 33 and 72.5 from 2 BALs & $\begin{array}{c}\text { I CFU A. fumigatus in BAL fluid; patchy nodular } \\
\text { infiltrates on CT; on ambisome for I0 days } \\
\text { prior to bronchoscopy }\end{array}$ \\
10 & positive & negative & $\begin{array}{c}\text { IPA Legionella CMV } \\
\text { pneumonia }\end{array}$ & 10 to 218 from 4 BALs & $\begin{array}{c}\text { I CFU A. niger in BAL with CT scan showing } \\
\text { halo sign, IPA confirmed at autopsy }\end{array}$
\end{tabular}

Additional information about false negative (FN) cases as identified by qPCR. Pt.: patient; DAH: Diffuse alveolar hemorrhage; CMV: Cytomegalovirus.

tion threshold of fungal burden (e.g. femtograms of DNA). This was useful in identifying the threshold of detection with an optimal trade-off between diagnostic sensitivity and specificity. The ROC analysis showed that a detection threshold of $13 \mathrm{fg}$ of Aspergillus DNA per pellet generated a sensitivity and specificity of $76.9 \%$ and $87.7 \%$, respectively (Fig. 2). These data compare favorably to the sensitivity and specificity of both PCR and galactomannan antigen studies using BAL fluid published previously $[10,12]$. At this detection threshold and a prevalence of proven or probable IPA of $13.8 \%$, the NPV of Aspergillus qPCR assay was high at $94 \%$ and the PPV was 58\%, consistent with results from other studies using BAL to diagnose IPA [16]. In addition, the PPV of our qPCR was similar to the FDA approved serum GM test used on hematopoietic stem cell transplant patients $[35,36]$. The lower PPV reflects the relatively low prevalence of IPA when analyzed on a per episode basis. A high NPV is useful as it suggests that a patient is unlikely to have IPA if the test is negative, and this may spare the patient from receiving unnecessary antifungal treatment that was started empirically, though these results do not rule out infection with another fungus.

Some patients (7) did not meet standard criteria for IPA, but had consistently high levels of Aspergillus DNA in BAL fluid by qPCR, as documented by repeated detection in multiple qPCR assays performed on different days (Table 3 ). These cases may be false positives due to fungal colonization of the airways, fungal contamination at the time of BAL collection, or true positives indicative of shortcomings in the EORTC/MSG criteria for defining IPA. Several of these patients had a diagnosis of idiopathic pneumonia syndrome or related pulmonary conditions after hematopoietic cell transplantation and were treated with mould-active antifungal medications empirically, thus the diagnosis of IPA cannot be completely excluded despite the absence of formal criteria for IPA. On the other hand, other patients did not receive mould-active antifungal therapy and did not appear to develop sequelae of IPA despite absence of treatment, suggesting that these episodes are definite false positives.

Among the 3 patients with false negative results, one had no evidence of Aspergillus in the original BAL sample using any diagnostic method, but proved to have IPA based on a subsequent lung biopsy. This false negative sample had the lowest amount of cellular material of all the BALs processed in this study which may reflect inadequate sampling of the lung segment at the time of bronchoscopy with BAL. Two patients with false negative PCRs for Aspergillus had 1 CFU of Aspergillus detected in BAL fluid by culture. This failure to detect Aspergillus DNA in the BAL fluid from these 2 subjects may reflect the low burden of fungal organisms, or may reflect the fact that these culture results are false positives (laboratory contamination), leading to improper classification using EORTC/MSG criteria.

There are several limitations of our study. First, the BAL procedure is highly variable which may impact the amount of fungal cells sampled from the site of infection. Second, significant portions of BAL were sent for other microbiological tests like histology and culture. There could be an impact of uneven distribution of fungi in the BAL between aliquots submitted for these various tests. In addition, the sensitivity of our study may have increased if larger volumes of BAL were processed. Third, we do not have serum or BAL galactomannan data for these subjects, which limit our ability to compare PCR performance with another molecular diagnostic test. Fourth, based on the EORTC/MSG criteria, culture was primarily used as a gold standard in defining IPA. This may have led to an overestimate of sensitivity and specificity of culture in our study.

In our study, quantitative PCR was about as sensitive as culture or culture with histology combined (Table 2). In contrast to culture, qPCR results can be generated in one day. Although culture was equally sensitive in detecting IPA in this study, it should be noted that this result probably reflects the critical role that cultivation played in 
defining subjects with IPA using EORTC/MSG criteria in this study. Several studies in the past have reported the sensitivity of BAL culture to be relatively low $(<50 \%)$ $[4,7,8]$. Of the 13 episodes with proven or probable IPA, culture and Aspergillus qPCR (with a $13 \mathrm{fg}$ detection threshold) were concurrently positive for 8 episodes. There were 2 episodes when culture was negative and qPCR was positive and 3 episodes when culture was positive and qPCR negative. In addition, qPCR was always positive when histology was positive. This implies that when qPCR is conjunctively used with culture, sensitivity of detecting IPA could approach $100 \%$, though much larger numbers of samples will be needed to define the true sensitivity and specificity of the qPCR assay. The significant correlation of fungal burden estimated by qPCR and the CFUs reported by culture tests implies qPCR is highly likely to be positive when culture and/or histology are positive. This result is in concordance with several published studies $[15,18,34,37]$.

\section{Conclusion}

Our Aspergillus qPCR assay detected Aspergillus DNA in $76.9 \%$ of subjects with proven or probable IPA when the concentrated BAL fluid pellet fraction was used for diagnosis. There was no benefit from analyzing the BAL supernatant fraction. Use of both extraction and amplification controls provided optimal quality control for interpreting qPCR results. PCR inhibitors detected in samples by the IAC could be removed with re-extraction of the DNA. Some patients did not meet standard criteria for IPA, but had consistently high levels of Aspergillus DNA in BAL fluid by qPCR suggesting that the FPs may result from colonization of the airways or shortcomings of the MSG/ EORTC classification criteria. Future studies will involve additional testing of BAL samples where the performance of galactomannan antigen assay is also evaluated. The rigorous quality control steps incorporated in our qPCR assay significantly enhance the reliability of the results and therefore may increase our understanding of the true potential of qPCR for the diagnosis of IPA.

\section{Competing interests}

The authors declare that they have no competing interests.

\section{Authors' contributions}

PDK helped to design the study, developed and optimized the qPCR assays, performed data analysis, and drafted the manuscript. DLK participated in the design of the study, assisted with the development, optimization, and implementation of the qPCR assays, and helped to draft the manuscript. RCH facilitated the collection and storage of BAL samples, was responsible for histological analysis of samples, and critically reviewed the manuscript. DNF conceived of the study, participated in the design of the study, categorized patients into diagnostic groups, assisted with data analysis, and helped to draft and review the manuscript. All authors read and approved the final manuscript.

\section{Acknowledgements}

Supported by NIH grant ROI AI054703 from the National Institute of Allergy and Infectious Diseases.

\section{References}

I. Segal BH, Walsh TJ: Current approaches to diagnosis and treatment of invasive aspergillosis. Am J Respir Crit Care Med 2006, I 73(7):707-7| 7

2. McNeil MM, Nash SL, Hajjeh RA, Phelan MA, Conn LA, Plikaytis BD, Warnock DW: Trends in Mortality Due to Invasive Mycotic Diseases in the United States, 1980-1997. Clinical Infectious Diseases 200I, 33(5):64I-647.

3. Munoz P, Guinea J, Bouza E: Update on invasive pulmonary aspergillosis: clinical and diagnostic aspects. Clin Microbiol Infect 2006, I 2 Suppl 7:24-39.

4. Reichenberger F, Habicht JM, Gratwohl A, Tamm M: Diagnosis and treatment of invasive pulmonary aspergillosis in neutropenic patients. Eur Respir J 2002, I 9(4):743-755.

5. Latge JP: Aspergillus fumigatus and aspergillosis. Clin Microbiol Rev 1999, I 2(2):3 10-350.

6. Reichenberger F, Habicht J, Matt $P$, Frei R, Soler M, Bolliger CT, Dalquen P, Gratwohl A, Tamm M: Diagnostic yield of bronchoscopy in histologically proven invasive pulmonary aspergillosis. Bone Marrow Transplant 1999, 24( I I): I I 95-I I 99.

7. Levy H, Horak DA, Tegtmeier BR, Yokota SB, Forman SJ: The value of bronchoalveolar lavage and bronchial washings in the diagnosis of invasive pulmonary aspergillosis. Respir Med 1992 , 86(3):243-248.

8. Saito H, Anaissie EJ, Morice RC, Dekmezian R, Bodey GP: Bronchoalveolar lavage in the diagnosis of pulmonary infiltrates in patients with acute leukemia. Chest 1988, 94(4):745-749.

9. Adam O, Auperin A, Wilquin F, Bourhis JH, Gachot B, Chachaty E: Treatment with piperacillin-tazobactam and false-positive Aspergillus galactomannan antigen test results for patients with hematological malignancies. Clin Infect Dis 2004, 38(6):917-920.

10. Aquino VR, Goldani LZ, Pasqualotto AC: Update on the contribution of galactomannan for the diagnosis of invasive aspergillosis. Mycopathologia 2007, I63(4): 191-202.

I I. Kedzierska A, Kochan P, Pietrzyk A, Kedzierska J: Current status of fungal cell wall components in the immunodiagnostics of invasive fungal infections in humans: galactomannan, mannan and (1-->3)-beta-D-glucan antigens. Eur J Clin Microbiol Infect Dis 2007, 26( I I):755-766.

12. Tuon FF: A systematic literature review on the diagnosis of invasive aspergillosis using polymerase chain reaction (PCR) from bronchoalveolar lavage clinical samples. Rev Iberoam Micol 2007, 24(2):89-94.

13. Buchheidt D, Baust C, Skladny H, Ritter J, Suedhoff T, Baldus M, Seifarth W, Leib-Moesch C, Hehlmann R: Detection of Aspergillus species in blood and bronchoalveolar lavage samples from immunocompromised patients by means of 2-step polymerase chain reaction: clinical results. Clin Infect Dis 200I, 33(4):428-435.

14. Hayette MP, Vaira D, Susin F, Boland P, Christiaens G, Melin P, De Mol P: Detection of Aspergillus species DNA by PCR in bronchoalveolar lavage fluid. J Clin Microbiol 200I, 39(6):2338-2340.

15. Musher B, Fredricks D, Leisenring W, Balajee SA, Smith C, Marr KA: Aspergillus galactomannan enzyme immunoassay and quantitative PCR for diagnosis of invasive aspergillosis with bronchoalveolar lavage fluid. J Clin Microbiol 2004, 42(I 2):55 I 7-5522.

16. Raad I, Hanna H, Huaringa A, Sumoza D, Hachem R, Albitar M: Diagnosis of invasive pulmonary aspergillosis using polymerase chain reaction-based detection of aspergillus in BAL. Chest 2002, I 2 I(4): I I71-II76.

17. Rantakokko-Jalava K, Laaksonen S, Issakainen J, Vauras J, Nikoskelainen J, Viljanen MK, Salonen J: Semiquantitative detection by real-time PCR of Aspergillus fumigatus in bronchoalveolar 
lavage fluids and tissue biopsy specimens from patients with invasive aspergillosis. J Clin Microbiol 2003, 4 I (9):4304-43 I I.

18. Sanguinetti M, Posteraro B, Pagano L, Pagliari G, Fianchi L, Mele L, La Sorda M, Franco A, Fadda G: Comparison of real-time PCR, conventional $P C R$, and galactomannan antigen detection by enzyme-linked immunosorbent assay using bronchoalveolar lavage fluid samples from hematology patients for diagnosis of invasive pulmonary aspergillosis. J Clin Microbiol 2003, 4 I (8):3922-3925.

19. Spiess B, Buchheidt D, Baust C, Skladny H, Seifarth W, Zeilfelder U, Leib-Mosch C, Morz H, Hehlmann R: Development of a LightCycler PCR assay for detection and quantification of Aspergillus fumigatus DNA in clinical samples from neutropenic patients. J Clin Microbiol 2003, 4 I (5): 18 II - I8I 8.

20. Paterson RR: Internal amplification controls have not been employed in fungal PCR hence potential false negative results. J Appl Microbiol 2007, I 02(I): I-I0.

21. Loeffler J, Hebart H, Bialek R, Hagmeyer L, Schmidt D, Serey FP, Hartmann $M$, Eucker J, Einsele $H$ : Contaminations occurring in fungal PCR assays. J Clin Microbiol 1999, 37(4): I200-I 202.

22. Bretagne S: Molecular diagnostics in clinical parasitology and mycology: limits of the current polymerase chain reaction (PCR) assays and interest of the real-time PCR assays. Clin Microbiol Infect 2003, 9(6):505-5I I.

23. Ascioglu S, Rex JH, de Pauw B, Bennett JE, Bille J, Crokaert F, Denning DW, Donnelly JP, Edwards JE, Erjavec Z, Fiere D, Lortholary O, Maertens J, Meis JF, Patterson TF, Ritter J, Selleslag D, Shah PM, Stevens DA, Walsh T]: Defining opportunistic invasive fungal infections in immunocompromised patients with cancer and hematopoietic stem cell transplants: an international consensus. Clin Infect Dis 2002, 34(I):7-14.

24. Limaye AP, Huang ML, Leisenring W, Stensland L, Corey L, Boeckh M: Cytomegalovirus (CMV) DNA load in plasma for the diagnosis of CMV disease before engraftment in hematopoietic stem-cell transplant recipients. J Infect Dis 200I, 183(3):377-382.

25. Ferns RB: Evaluation of the role of real-time PCR in the diagnosis of invasive aspergillosis. Leuk Lymphoma 2006, 47( I): I5-20

26. Ou CY, Moore JL, Schochetman G: Use of UV irradiation to reduce false positivity in polymerase chain reaction. Biotechniques I991, I0(4):442, 444, 446.

27. Wages JM Jr., Cai D, Fowler AK: Removal of contaminating DNA from PCR reagents by ultrafiltration. Biotechniques 1994, 16(6):1014-1017.

28. Jordan JA, Durso MB: Comparison of I6S rRNA gene PCR and BACTEC 9240 for detection of neonatal bacteremia. J Clin Microbiol 2000, 38(7):2574-2578.

29. Loffler J, Hebart H, Schumacher U, Reitze H, Einsele H: Comparison of different methods for extraction of DNA of fungal pathogens from cultures and blood. J Clin Microbiol 1997 35(I 2):33|I-33|2.

30. Fredricks DN, Smith C, Meier A: Comparison of six DNA extraction methods for recovery of fungal DNA as assessed by quantitative PCR. J Clin Microbiol 2005, 43( I0):5 I22-5I 28.

31. Griffiths LJ, Anyim M, Doffman SR, Wilks M, Millar MR, Agrawal SG: Comparison of DNA extraction methods for Aspergillus fumigatus using real-time PCR. J Med Microbiol 2006, 55(Pt 9): | |87-II9|

32. Hoorfar J, Malorny B, Abdulmawjood A, Cook N, Wagner M, Fach P: Practical considerations in design of internal amplification controls for diagnostic PCR assays. J Clin Microbiol 2004, 42(5): $1863-1868$

33. Caliendo AM, Hewitt PL, Allega JM, Keen A, Ruoff KL, Ferraro MJ: Performance of a PCR assay for detection of Pneumocystis carinii from respiratory specimens. J Clin Microbiol 1998, 36(4):979-982.

34. Bretagne S, Costa JM, Marmorat-Khuong A, Poron F, Cordonnier C Vidaud M, Fleury-Feith J: Detection of Aspergillus species DNA in bronchoalveolar lavage samples by competitive PCR. J Clin Microbiol 1995, 33(5): I |64-II68.

35. Herbrecht R, Letscher-Bru V, Oprea C, Lioure B, Waller J, Campos F, Villard O, Liu KL, Natarajan-Ame S, Lutz P, Dufour P, Bergerat JP, Candolfi E: Aspergillus galactomannan detection in the diagnosis of invasive aspergillosis in cancer patients. I Clin Oncol 2002, 20(7): 1898-1906
36. Pfeiffer $C D$, Fine JP, Safdar N: Diagnosis of invasive aspergillosis using a galactomannan assay: a meta-analysis. Clin Infect Dis 2006, 42(10): 1417-I427.

37. Spreadbury C, Holden D, Aufauvre-Brown A, Bainbridge B, Cohen J: Detection of Aspergillus fumigatus by polymerase chain reaction. J Clin Microbiol I993, 3 I (3):6 I5-62I.

\section{Pre-publication history}

The pre-publication history for this paper can be accessed here:

http://www.biomedcentral.com/1471-2334/8/73/prepub
Publish with BioMed Central and every scientist can read your work free of charge

"BioMed Central will be the most significant development for disseminating the results of biomedical research in our lifetime. "

Sir Paul Nurse, Cancer Research UK

Your research papers will be:

- available free of charge to the entire biomedical community

- peer reviewed and published immediately upon acceptance

- cited in PubMed and archived on PubMed Central

- yours - you keep the copyright 